\title{
NoD: a Nucleolar localization sequence detector for eukaryotic and viral proteins
}

\author{
Michelle S Scott*, Peter V Troshin and Geoffrey J Barton
}

\begin{abstract}
Background: Nucleolar localization sequences (NoLSs) are short targeting sequences responsible for the localization of proteins to the nucleolus. Given the large number of proteins experimentally detected in the nucleolus and the central role of this subnuclear compartment in the cell, NoLSs are likely to be important regulatory elements controlling cellular traffic. Although many proteins have been reported to contain NoLSs, the systematic characterization of this group of targeting motifs has only recently been carried out.

Results: Here, we describe NoD, a web server and a command line program that predicts the presence of NoLSs in proteins. Using the web server, users can submit protein sequences through the NoD input form and are provided with a graphical output of the NoLS score as a function of protein position. While the web server is most convenient for making prediction for just a few proteins, the command line version of NoD can return predictions for complete proteomes. NoD is based on our recently described human-trained artificial neural network predictor. Through stringent independent testing of the predictor using available experimentally validated NoLS-containing eukaryotic and viral proteins, the NoD sensitivity and positive predictive value were estimated to be $71 \%$ and $79 \%$ respectively.

Conclusions: NoD is the first tool to provide predictions of nucleolar localization sequences in diverse eukaryotes and viruses. NoD can be run interactively online at http://www.compbio.dundee.ac.uk/nod or downloaded to use locally.
\end{abstract}

Keywords: nucleolus, protein targeting signal, protein localization, NoD web server

\section{Background}

The nucleolus is a sub-nuclear cellular compartment that is accessible to a large number of proteins since it is not surrounded by a membrane. To date, over 4500 distinct human proteins have been identified from purified nucleoli [1]. The most well-characterized function of the nucleolus is the biogenesis of ribosomes [2]. However, nucleolar proteins are diverse and dynamic, reflecting the central role of this compartment in the cell through its involvement in numerous other key cellular processes and in the cellular response to changing conditions [3-7]. Indeed, many proteins have been found to localize cyclically or conditionally to the nucleolus $[3,4,7,8]$.

Although such a large and dynamic volume of cellular traffic likely requires extensive regulation, proteins are

\footnotetext{
* Correspondence: michelle@compbio.dundee.ac.uk

Division of Biological Chemistry and Drug Discovery, College of Life Sciences, University of Dundee, Dow Street, Dundee DD1 5EH, UK
}

often proposed to localize to the nucleolus simply through high-affinity binding to core nucleolar components $[6,9]$. Despite this, numerous disparate reports of short nucleolar targeting sequences in proteins have been published over the past 20 years. Many of these sequences can localize non-nucleolar reporter proteins to the nucleolus when fused to them. In an effort to catalogue and systematically characterize these Nucleolar Localization Sequences (NoLSs), we have recently curated the literature and assembled a human NoLS dataset which we subsequently used to train an artificial neural network computational predictor [10]. The predictor considers the protein sequence and JPred predictions of protein secondary structure [11]. When applied to the entire human proteome, it identified thousands of candidate NoLSs, ten of which were experimentally tested and confirmed to target the nucleolus [10].

Here, we describe NoD, a web server and a commandline program that provides computer predictions of NoLSs in proteins. We also investigate the application
C Biomed Central 
of the human-trained predictor in other eukaryotic and viral organisms, demonstrating that $\mathrm{NoD}$ can give effective NoLS predictions in a wide variety of species.

\section{Implementation}

The NoD web server provides an easy way to predict NoLSs within a protein sequence. NoD predictions are obtained by entering a protein sequence in fasta format on the NoD webserver http://www.compbio.dundee.ac. $\mathrm{uk} /$ nod. Protein sequences are encoded as previously described [10]. Briefly, sliding windows of size 13 are sparsely encoded in a binary format using a reduced alphabet of size 12 for submission to an artificial neural network (ANN). The current implementation of NoD uses a local version of Batchman from the Stuttgart Neural Network Simulator [12] and the human-trained NoLS prediction model developed previously [10] to provide the prediction for each encoded subsequence. The Batchman output is then processed and NoLSs are predicted if the average score output by the ANN of 8 consecutive windows is at least 0.8 [10]. Finally, the prediction is displayed as shown in Figure 1 if at least one NoLS is identified. Otherwise, the user is informed that no NoLS is predicted in the input protein. As shown in
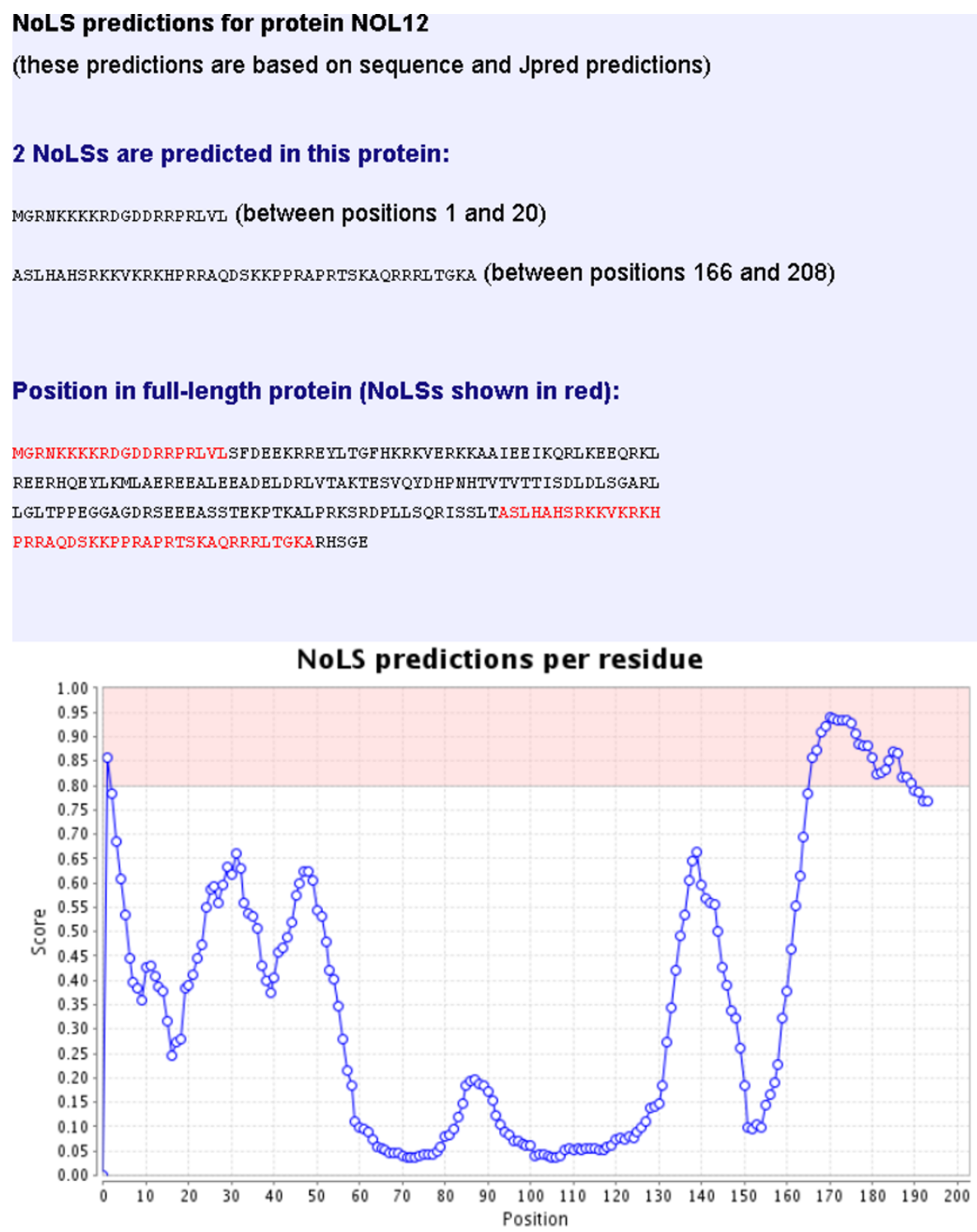

Figure 1 Example of NoLS prediction returned by NoD. If at least one NoLS is predicted in a protein, NoD returns an output page that displays the sequence and position of the predicted NoLSs, the full-length protein sequence as entered by the user with the NoLSs in red and a graph showing the average NoLS prediction score for every 20-residue window in the protein. The region shown in pink in this graph is the NoLS candidate segment region and represents the range of scores within which a 20-residue segment is predicted to be a NoLS. 
Figure 1, for proteins predicted to contain NoLS(s), the output consists of 3 sections:

- the sequences of the predicted NoLS(s) are first enumerated

- the full-length protein sequence is displayed with the predicted NoLS(s) shown in red

- finally, a graph is presented of the NoLS windowbased score [10] as a function of position in the protein sequence.

The NoLS window-based score graph can be useful to guide experimental design of nucleolar targeting. The graph gives an overview of the entire protein and shows the proportion of the protein with putative nucleolar targeting capabilities as well as regions of the protein that are near the cut-off threshold and therefore almost predicted as NoLSs.

When entering a protein sequence, the user is provided with the option of also running JPred secondary structure predictions [11] to include as input to the NoLS neural network. If JPred is selected, the accuracy of prediction is slightly higher [10] but the computation time is increased.

For users who want predictions for whole proteomes there is a command line version of NoD called clinod. Clinod produces the same results as a web server but it is more suitable for processing of multiple sequences and is convenient to use within software pipelines.

Clinod requires Java 6 and the Batchman executable from the Stuttgart Neural Network Simulator [12] to run. Clinod accepts the list of FASTA formatted sequences from an input file and outputs the predictions to a file or the console. By default the following output is produced for each sequence-the name of the sequence, the number of NoLSs predicted, the start and the end positions and the sequences of each predicted NoLS. However, for better integration with other bioinformatics tools, many more output options are supported. For example, the input sequences can be cleaned (stripped of ambiguous characters), and output along with the prediction results and sequences with no predicted NoLS can be omitted from the output. Various output options are described in Table 1 but for a detailed description of the clinod switches please refer to Additional file 1.

Finally, for users preferring to run and visualize their predictions locally, there is a virtual appliance version of NoD, which can easily be deployed on a variety of operating systems by a non-specialist user. The virtual appliance version of NoD offers the same functionality as our public server, with the exception of JPred predictions. However, in the near future we intend to release a version which will support JPred.

Table 1 Clinod output formats

\begin{tabular}{|c|c|c|}
\hline $\begin{array}{l}\text { Format } \\
\text { name }\end{array}$ & Format Description & Example output ${ }^{a}$ \\
\hline MINIMAL & $\begin{array}{c}\text { Sequence name and number of } \\
\text { NOLS predicted }\end{array}$ & $\begin{array}{l}\text { > NOL12 } \\
\text { NOLS_segment_number: } 2\end{array}$ \\
\hline SHORT & $\begin{array}{l}\text { Same as MINIMAL plus, start and } \\
\text { end position of each NOLS }\end{array}$ & $\begin{array}{c}\text { > NOL12 } \\
\text { NOLS_segment_number: } 2 \\
\text { NOLS_segments_positions: 1-20, 165-213 }\end{array}$ \\
\hline $\begin{array}{l}\text { MEDIUM } \\
\text { (default) }\end{array}$ & $\begin{array}{l}\text { Same as SHORT plus the } \\
\text { sequences of all NOLS }\end{array}$ & $\begin{array}{c}\text { N NOL12 } \\
\text { NOLS_segment_number: } 2 \\
\text { NOLS_segments_positions: } 1-20,165-213 \\
\text { NOLS_segments: MGRNKKKKRDGDDRRPRLVL, TASLHAHSRKKVKRRLTGKARHSGE }\end{array}$ \\
\hline FULL & $\begin{array}{l}\text { Same as MEDIUM plus the } \\
\text { predictor score for each residue } \\
\text { in the sequence }\end{array}$ & $\begin{array}{c}\text { > NOL12 } \\
\text { NOLS_segment_number: } 2 \\
\text { NOLS_segments_positions: } 1 \text {-20, 165-213 } \\
\text { NOLS_segments: MGRNKKKKRDGDDRRPLVL, TASLHAHSRKKVKRRLTGKARHSGE } \\
0.87 \\
0.79 \\
0.69 \\
\ldots\end{array}$ \\
\hline COMPLETE & $\begin{array}{l}\text { Same as FULL plus the input } \\
\text { sequences }\end{array}$ & $\begin{array}{c}\text { > NOL12 } \\
\text { MGRNKKKKRDGDDRRPRLVLSFDEEKRREYLTGFHKRKVERKKAAIEEIKQRLKEEEQRKLREERHQEYLKMLAEREEALE... } \\
\text { NOLS_segment_number: } 2 \\
\text { NOLS_segments_positions: 1-20, 165-213 } \\
\text { NOLS_segments: MGRNKKKKRDGDDRRPRLVL, TASLHAHSRKKVKRRLTGKARHSGE } \\
0.87 \\
0.79 \\
0.69 \\
\ldots\end{array}$ \\
\hline
\end{tabular}

\footnotetext{
${ }^{a}$ The sequences and scores are truncated in the Table for clarity of presentation.
} 


\section{Results and Discussion}

\section{Prediction of NoLSs in non-human eukaryotes}

Because more NoLSs have been reported in human than in all other organisms combined, the NoLS predictor was originally trained and tested only on human sequences [10]. More precisely, as described previously [10], the predictor was trained on a manually curated positive set of 46 human experimentally validated NoLSs and a negative set consisting of several hundred human proteins chosen because they are believed not to localize to the nucleolus. After training, ten of the NoLS predictions were chosen for experimental validation and all were confirmed as positives [10].
However, the prediction of NoLSs is relevant in all eukaryotes and in particular in their viruses, many of which encode proteins that localize to the nucleolus of their host cells [13]. To investigate whether the humantrained predictor can be applied to other organisms, we searched the literature to find examples of NoLSs that have been experimentally identified in other organisms. In total, we collated 31 eukaryotic or viral NoLSs (including 6 human NoLSs that had not been used for training or testing previously) which are listed in Table 2 , along with the position of the experimentally determined NoLSs. Sequences were filtered to remove redundancy within this dataset and redundancy with the

Table 2 Detail of NoD predictions on the multi-organism testing dataset assembled

\begin{tabular}{|c|c|c|c|c|c|}
\hline Organism & $\begin{array}{l}\text { Protein } \\
\text { Accession }\end{array}$ & Name & $\begin{array}{l}\text { Experimentally determined NoLS } \\
\text { position }\end{array}$ & NoD prediction & $\operatorname{Ref}^{a}$ \\
\hline Homo sapiens & NP_001012333 & Midkine & $129-143$ & $120-143$ & [19] \\
\hline Homo sapiens & NP_055701 & NSA2 & $10-41$ & no NoLS & {$[20]$} \\
\hline Homo sapiens & NP_055701 & NSA2 & $131-154$ & $133-155$ & [20] \\
\hline Homo sapiens & NP_872604 & RASSF5 & $51-100$ & $78-98$ & {$[21]$} \\
\hline Homo sapiens & NP_037541 & follistatin & $93-116^{b}$ & $98-121$ & {$[22]$} \\
\hline Homo sapiens & CAA41051 & histone $\mathrm{H} 2 \mathrm{~B}$ & $28-35$ & $15-42$ & [23] \\
\hline Mus musculus & NP_001012495 & $\mathrm{CxCl12}$ & $98-118$ & $92-119$ & [24] \\
\hline Mus musculus & NP_081208 & NoBP & $220-262$ & 230-255 and 276-306 & {$[25]$} \\
\hline Mus musculus & NP_082355 & aminopeptidase $\mathrm{O}$ & $688-725$ & $682-712$ & {$[26]$} \\
\hline Dictyostelium discoideum & XP_002649205 & elF6 & $31-64$ & $27-49$ & [27] \\
\hline Dictyostelium discoideum & XP_002649205 & elF6 & $246-252$ & $295-320$ & {$[27]$} \\
\hline Aplysia kurodai & BOFRH7 & ApLLP & $1-19$ & $1-21$ & {$[28]$} \\
\hline Aplysia kurodai & BOFRH7 & ApLLP & $90-120$ & $96-120$ & {$[28]$} \\
\hline Trypanosome brucei & CAD21884 & ESAG8 & $48-79$ & no NoLS & [14] \\
\hline Trypanosome cruzi & XP_817097 & Met-III & $1-19$ & No NoLS & [29] \\
\hline Trypanosome cruzi & XP_817097 & Met-III & 146-191 & No NoLS & [29] \\
\hline Solanum lycopersicum & Q944N1 & LHP1 & $141-171$ & 141-165 and 276-296 & {$[30]$} \\
\hline Arabidopsis thaliana & NP_001078269 & HMGB1 & $1-47$ & $22-60$ & [31] \\
\hline Bovine herpesvirus 1 & CAA90914 & $\mathrm{BICP} 27$ & $86-97$ & $75-108$ & {$[32]$} \\
\hline Human Adenovirus C & YP_001551773 & E4orf4 & $66-75$ & $61-82$ & [33] \\
\hline SARS & P59633 & $\begin{array}{l}\text { Non-structural protein } \\
3 \mathrm{~b}\end{array}$ & $134-154$ & No NoLS & {$[34]$} \\
\hline HTLV-1 & BAH85789 & Tof & $71-98$ & No NoLS & {$[35]$} \\
\hline Human herpes simplex & P08353 & Gamma-1 34.5 protein & $1-16$ & $1-22$ & {$[36]$} \\
\hline Human adenovirus 2 & P68950 & protein VII & $93-112$ & $90-117$ & [15] \\
\hline African Swine Fever Virus & AAA87288 & I14L & $1-14$ & $1-26$ & {$[37]$} \\
\hline PRRSV (porcine) & AAD00244 & $\mathrm{N}$ protein & $41-48$ & $1-21$ and 32-59 & {$[38]$} \\
\hline Tomato Leaf Curl Java Virus & BAD90868 & Capsid protein & $1-30$ & no NoLS & {$[39]$} \\
\hline Potato leafroll virus & P11624 & Capsid protein & $17-31$ & $10-64$ & {$[40]$} \\
\hline Marek's disease virus type 1 & AAS01627 & MEQ protein & $62-78$ & $22-47$ and $52-81$ & {$[41]$} \\
\hline $\begin{array}{l}\text { Avian Infectious Bronchitis } \\
\text { Virus }\end{array}$ & CAC39307 & $\mathrm{N}$ protein & $71-78$ & $347-377$ & {$[42]$} \\
\hline Betanodavirus GGNNV & NP_689432 & Protein alpha & $23-31$ & $10-40$ & [43] \\
\hline
\end{tabular}

a Ref: Reference reporting the experimental NoLS identification

${ }^{b}$ In [22], the NoLS for follistatin is reported at positions 64-87. These correspond to the positions in the protein once the signal peptide has been removed. 
original training set as described previously [10]. The full-length sequences of these NoLS-containing proteins were then passed through the NoLS predictor. As with the original NoLS paper [10], only experimentally validated NoLSs of length less than 50 residues were considered for testing. This focuses the testing on those NoLSs that have been most confidently identified by experiment and reduces the likelihood that we are dealing with signal patches (ie signals formed from residues distant in the primary sequence but that come into close proximity in the folded molecule). We considered NoLSs as correctly-predicted if the region of overlap between the predicted NoLS and the experimentally determined NoLS covered at least $60 \%$ of the shortest of the two molecules. In many cases, the predicted NoLS region is entirely contained within the experimentally determined NoLS or vice versa. Details of the predictions, including the position of predicted NoLSs, are given in Table 2 and a summary of the prediction accuracy is given in Table 3.

As shown in Table 3, mammalian NoLSs and their viral counterparts are well predicted, with sensitivity and positive predictive values ranging from 0.75 to 1.0. This is not surprising because of the close evolutionary distance between humans and other mammals and the constant adaptation of their viruses. Amongst the nonmammalian proteins considered, the Dictyostelium discoideum protein investigated has two NoLSs, one of which is well-predicted. The NoLS that was not correctly identified consists of only 7 amino acids and is likely too short for the predictor to find. The two mollusc NoLSs are entirely well-predicted but low numbers of examples in this group of organisms prevents robust conclusions. Similarly, plant and plant-infecting virus NoLSs are generally well-predicted but also suffer from small numbers of examples. However, the humantrained predictor is entirely incapable of identifying the NoLSs experimentally detected in trypanosomes. This agrees well with experiments in which the NoLS of a Trypanosome brucei protein, ESAG8, was fused to a fluorescent reporter protein and tested for nucleolar localization in human cells. With an intact trypanosome NoLS, the fusion protein was found to be nuclear but not nucleolar in human cells [14]. This observation and our predictions suggest that nucleolar targeting mechanisms differ significantly between humans and trypanosomes and are not interchangeable. Although a larger sample would be needed to confirm this difference,

Table 3 Accuracy of NoD predictions in all organisms investigated

\begin{tabular}{|c|c|c|c|c|c|c|c|}
\hline & distinct protein count & NoLS count & $\mathrm{TP}^{a}$ count & FP $^{b}$ count & Sensitivity & $\mathrm{PPV}^{c}$ & Specificity $^{d}$ \\
\hline \multicolumn{8}{|l|}{ A. Eukaryotes } \\
\hline Mammals $^{\mathrm{e}}$ & 8 & 9 & 8 & 1 & 0.89 & 0.89 & 0.88 \\
\hline H. sapiens & 5 & 6 & 5 & 0 & 0.83 & 1.0 & 1.0 \\
\hline M. musculus & 3 & 3 & 3 & 1 & 1.0 & 0.75 & 0.67 \\
\hline Amoeba $^{\mathrm{e}}$ & 1 & 2 & 1 & 1 & 0.5 & 0.5 & 0.0 \\
\hline Dictyostelium discoideum & 1 & 2 & 1 & 1 & 0.5 & 0.5 & 0.0 \\
\hline Molluscs $^{e}$ & 1 & 2 & 2 & 0 & 1.0 & 1.0 & 1.0 \\
\hline A. kurodai & 1 & 2 & 2 & 0 & 1.0 & 1.0 & 1.0 \\
\hline Trypanosomes ${ }^{\mathrm{e}}$ & 2 & 3 & 0 & 0 & 0 & N/A & 1.0 \\
\hline T. brucei & 1 & 1 & 0 & 0 & 0 & $\mathrm{~N} / \mathrm{A}$ & 1.0 \\
\hline T. cruzi & 1 & 2 & 0 & 0 & 0 & N/A & 1.0 \\
\hline Plants $^{\mathrm{e}}$ & 2 & 2 & 2 & 1 & 1.0 & 0.67 & 0.5 \\
\hline S. lycopersicum & 1 & 1 & 1 & 1 & 1.0 & 0.50 & 0.0 \\
\hline A. thaliana & 1 & 1 & 1 & 0 & 1.0 & 1.0 & 1.0 \\
\hline \multicolumn{8}{|l|}{ B. Viruses } \\
\hline Mammalian host & 8 & 8 & 6 & 1 & 0.75 & 0.86 & 0.88 \\
\hline Plant host & 2 & 2 & 1 & 0 & 0.5 & 1.0 & 1.0 \\
\hline Avian host & 2 & 2 & 1 & 2 & 0.5 & 0.33 & 0.0 \\
\hline Fish host & 1 & 1 & 1 & 0 & 1.0 & 1.0 & 1.0 \\
\hline \multicolumn{8}{|l|}{ a TP: true positive } \\
\hline \multicolumn{8}{|l|}{${ }^{\mathrm{b}} \mathrm{FP}$ : false positive } \\
\hline \multicolumn{8}{|c|}{ ' PPV: positive predictive value } \\
\hline \multicolumn{8}{|c|}{$\begin{array}{l}\text { d The specificity was calculated as the number of proteins considered for which no FP was identified divided by the number of proteins considered (this defines } \\
\text { all non NoLS regions as negatives). }\end{array}$} \\
\hline \multicolumn{8}{|c|}{$\begin{array}{l}\text { e For each of the count columns, the top row of each of the subsections in the Eukaryotes section represents the sum of the rows below it belonging to this } \\
\text { subsection. }\end{array}$} \\
\hline
\end{tabular}


trypanosomal nucleolar targeting mechanisms might represent good drug targets.

While no experimentally generated negative dataset is available for testing the predictor in non-human organisms, we note that the non-NoLS regions of NoLS-containing proteins provide such a set. For example, the human adenovirus 2 protein VII encodes three basic regions at positions 47-54, 93-112 and 127-141 which represent possible nuclear/nucleolar localization sequences [15]. Deletion constructs demonstrate that only the 93-112 segment targets a reporter protein to the nucleolus [15]. This segment matches very closely the NoD NoLS predictions (see Table 2), providing not only an accurate test example but also perfect negative controls (the two other basic regions are not predicted as NoLSs). Thus, the positive predictive values shown in Table 3 give an indication of the false positive rate of prediction in different organisms. However, while some false positives probably represent prediction errors, others might have occurred because NoLSs were not experimentally mapped with enough precision or more than one NoLS exists in the protein. Larger experimental datasets will undoubtedly help to clarify this problem.

Of the 31 eukaryotic and viral NoLSs considered for independent testing, 22 were correctly identified, resulting in an overall sensitivity of $71 \%$. In addition, 6 nonNoLS regions were also identified as positives (and thus are considered here as false positives) yielding an overall positive predictive value of $79 \%$. Finally, of the 27 proteins considered, 6 were predicted to encode NoLSs in regions not experimentally shown to harbour a NoLS resulting in a specificity of $78 \%$ (although we note that some of these false positives might represent NoLSs that have yet to be experimentally identified).

\section{Conclusions}

$\mathrm{NoD}$ is currently the only predictor capable of providing and visualizing NoLS predictions for protein sequences.

The web server takes a protein sequence as input and returns the positions and the sequences of the predicted NoLSs. It also draws a graph of the predicted scores for each residue of the sequence.

The command line NoD takes the list of FASTA formatted protein sequences as an input, and for each sequence outputs the number of detected NoLSs, their positions in the full-length sequence and their sequences. However, the command line predictor output is highly customisable and can be adjusted to the user's needs. Finally, the virtual appliance version of the predictor allows the deployment and running of the predictor locally, eliminating data privacy issues.

Cross-species testing shows NoD to perform best for mammalian and mammalian-infecting viral proteins but preliminary results suggest sequences from molluscs, amoebae, plants and their viruses are also wellpredicted.

\section{Availability and requirements}

- Project name: NoD (Nucleolar localization sequence Detector)

- Project home page: http://www.compbio.dundee. ac.uk/nod

- Operating system(s): Platform independent

- Programming language: Java

- Other requirements: The command line version requires Java 6 or higher, and the SNNS Batch Interpreter V1.0 [12]. The virtual appliance version requires freely available VMware Player 3.1 [16] or higher, commercial VMware Fusion (for Mac users) [17] or the freely available Oracle VirtualBox v3.2.12 [18]

- License: Apache 2

- Any restrictions to use by non-academics: no restrictions

\section{Additional material}

Additional file 1: NoD command line manual. The additional file

describes the usage of the NoD batch predictor command line utility.

\section{Acknowledgements and Funding}

We would like to thank Dr Tom Walsh for technical expertise. This work was supported by a post-doctoral fellowship from the Caledonian Research Foundation to MSS, by the Scottish Universities Life Sciences Alliance (SULSA), by the European Network of Excellence ENFIN [contract LSHG-CT2005-518254], and by Wellcome Trust grant WT083481.

\section{Authors' contributions}

MSS conceived the project and contributed to its design, carried out the acquisition and analysis of data, contributed to the implementation of the predictor and drafted the manuscript. PVT contributed to the design of the project, the implementation of the predictor and critically revised the manuscript. GJB contributed to the design of the project and critically revised the manuscript. All authors read and approved the final manuscript.

Received: 9 May 2011 Accepted: 3 August 2011

Published: 3 August 2011

\section{References}

1. Ahmad Y, Boisvert FM, Gregor P, Cobley A, Lamond Al: NOPdb: Nucleolar Proteome Database-2008 update. Nucleic Acids Res 2009, , 37 Database: D181-184.

2. Scheer U, Hock R: Structure and function of the nucleolus. Curr Opin Cell Biol 1999, 11(3):385-390.

3. Boisvert FM, Lam YW, Lamont D, Lamond Al: A quantitative proteomics analysis of subcellular proteome localization and changes induced by DNA damage. Mol Cell Proteomics 2010, 9(3):457-470.

4. Boisvert FM, van Koningsbruggen S, Navascues J, Lamond Al: The multifunctional nucleolus. Nat Rev Mol Cell Biol 2007, 8(7):574-585.

5. Olson MO, Hingorani K, Szebeni A: Conventional and nonconventional roles of the nucleolus. Int Rev Cytol 2002, 219:199-266.

6. Pederson T, Tsai RY: In search of nonribosomal nucleolar protein function and regulation. J Cell Biol 2009, 184(6):771-776. 
7. Andersen JS, Lam YW, Leung AK, Ong SE, Lyon CE, Lamond Al, Mann M: Nucleolar proteome dynamics. Nature 2005, 433(7021):77-83.

8. Pederson T: Growth factors in the nucleolus? J Cell Biol 1998, 143(2):279-281.

9. Carmo-Fonseca M, Mendes-Soares L, Campos I: To be or not to be in the nucleolus. Nat Cell Biol 2000, 2(6):E107-112.

10. Scott MS, Boisvert FM, McDowall MD, Lamond Al, Barton GJ: Characterization and prediction of protein nucleolar localization sequences. Nucleic Acids Res 2010, 38(21):7388-7399.

11. Cole C, Barber JD, Barton GJ: The Jpred 3 secondary structure prediction server. Nucleic Acids Res 2008, 36 Web Server: W197-201.

12. Stuttgart Neural Network Simulator. [http://www.ra.cs.uni-tuebingen.de/ SNNS/].

13. Hiscox JA: RNA viruses: hijacking the dynamic nucleolus. Nat Rev Microbiol 2007, 5(2):119-127.

14. Hoek M, Engstler M, Cross GA: Expression-site-associated gene 8 (ESAG8) of Trypanosoma brucei is apparently essential and accumulates in the nucleolus. J Cell Sci 2000, 113(Pt 22):3959-3968.

15. Lee TW, Blair GE, Matthews DA: Adenovirus core protein VII contains distinct sequences that mediate targeting to the nucleus and nucleolus, and colocalization with human chromosomes. J Gen Virol 2003, 84(Pt 12):3423-3428

16. VMware Player 3.1. [http://downloads.vmware.com/d/info/ desktop_downloads/vmware_player/3_0].

17. VMware Fusion. [http://downloads.vmware.com/d/info/ desktop_downloads/vmware_fusion_for_the_mac/3_0]

18. Oracle VirtualBox v3.2.12. [http://www.virtualbox.org/wiki/ Download_Old_Builds_3_2].

19. Dai $L, X u D$, Yao $X, L u Y, X u Z$ : Conformational determinants of the intracellular localization of midkine. Biochem Biophys Res Commun 2005, 330(1):310-317.

20. Zhang $H, M a X$, Shi T, Song Q, Zhao H, Ma D: NSA2, a novel nucleolus protein regulates cell proliferation and cell cycle. Biochem Biophys Res Commun 2010, 391(1):651-658.

21. Kumari G, Singhal PK, Rao MR, Mahalingam S: Nuclear transport of Rasassociated tumor suppressor proteins: different transport receptor binding specificities for arginine-rich nuclear targeting signals. $J \mathrm{Mol} B i \mathrm{O}$ 2007, 367(5):1294-1311

22. Gao X, Wei S, Lai K, Sheng J, Su J, Zhu J, Dong H, Hu H, Xu Z: Nucleolar follistatin promotes cancer cell survival under glucose-deprived conditions through inhibiting cellular rRNA synthesis. J Biol Chem 2010, 285(47):36857-36864

23. Musinova YR, Lisitsyna OM, Golyshev SA, Tuzhikov Al, Polyakov VY, Sheval EV: Nucleolar localization/retention signal is responsible for transient accumulation of histone $\mathrm{H} 2 \mathrm{~B}$ in the nucleolus through electrostatic interactions. Biochim Biophys Acta 2011, 1813(1):27-38.

24. Torres R, Ramirez JC: A chemokine targets the nucleus: Cxcl12-gamma isoform localizes to the nucleolus in adult mouse heart. PLOS ONE 2009, 4(10):e7570.

25. Reimers K, Antoine M, Zapatka M, Blecken V, Dickson C, Kiefer P: NoBP, a nuclear fibroblast growth factor 3 binding protein, is cell cycle regulated and promotes cell growth. Mol Cell Biol 2001, 21(15):4996-5007.

26. Axton $\mathrm{R}$, Wallis JA, Taylor $\mathrm{H}$, Hanks M, Forrester LM: Aminopeptidase $\mathrm{O}$ contains a functional nucleolar localization signal and is implicated in vascular biology. J Cell Biochem 2008, 103(4):1171-1182.

27. Catalano A, O'Day DH: Nucleolar localization and identification of nuclear/nucleolar localization signals of the calmodulin-binding protein nucleomorphin during growth and mitosis in Dictyostelium. Histochem Cell Biol 2011, 135(3):239-249.

28. Kim H, Chang DJ, Lee JA, Lee YS, Kaang BK: Identification of nuclear/ nucleolar localization signal in Aplysia learning associated protein of slug with a molecular mass of $18 \mathrm{kDa}$ homologous protein. Neurosci Lett 2003, 343(2):134-138

29. Gluenz E, Taylor MC, Kelly JM: The Trypanosoma cruzi metacyclic-specific protein Met-III associates with the nucleolus and contains independent amino and carboxyl terminal targeting elements. Int J Parasitol 2007, 37(6):617-625

30. Zemach A, Li Y, Ben-Meir H, Oliva M, Mosquna A, Kiss V, Avivi Y, Ohad N, Grafi G: Different domains control the localization and mobility of LIKE HETEROCHROMATIN PROTEIN1 in Arabidopsis nuclei. Plant Cell 2006, 18(1):133-145
31. Launholt D, Merkle T, Houben A, Schulz A, Grasser KD: Arabidopsis chromatin-associated HMGA and HMGB use different nuclear targeting signals and display highly dynamic localization within the nucleus. Plant Cell 2006, 18(11):2904-2918.

32. Ding $Q$, Guo $H$, Lin F, Pan W, Ye B, Zheng AC: Characterization of the nuclear import and export mechanisms of bovine herpesvirus-1 infected cell protein 27. Virus Res 149(1):95-103.

33. Miron MJ, Gallouzi IE, Lavoie JN, Branton PE: Nuclear localization of the adenovirus E4orf4 protein is mediated through an arginine-rich motif and correlates with cell death. Oncogene 2004, 23(45):7458-7468.

34. Yuan X, Yao Z, Shan Y, Chen B, Yang Z, Wu J, Zhao Z, Chen J, Cong Y: Nucleolar localization of non-structural protein $3 b$, a protein specifically encoded by the severe acute respiratory syndrome coronavirus. Virus Res 2005, 114(1-2):70-79.

35. D'Agostino DM, Ciminale V, Zotti L, Rosato A, Chieco-Bianchi L: The human T-cell lymphotropic virus type 1 Tof protein contains a bipartite nuclear localization signal that is able to functionally replace the amino-terminal domain of Rex. J Virol 1997, 71(1):75-83.

36. Cheng G, Brett ME, He B: Signals that dictate nuclear, nucleolar, and cytoplasmic shuttling of the gamma(1)34.5 protein of herpes simplex virus type 1. J Virol 2002, 76(18):9434-9445.

37. Goatley LC, Marron MB, Jacobs SC, Hammond JM, Miskin JE, Abrams CC, Smith GL, Dixon LK: Nuclear and nucleolar localization of an African swine fever virus protein, $114 \mathrm{~L}$, that is similar to the herpes simplex virus-encoded virulence factor ICP34.5. J Gen Virol 1999, 80(Pt 3):525-535.

38. Rowland RR, Schneider P, Fang Y, Wootton S, Yoo D, Benfield DA: Peptide domains involved in the localization of the porcine reproductive and respiratory syndrome virus nucleocapsid protein to the nucleolus. Virology 2003, 316(1):135-145.

39. Sharma P, Ikegami M: Characterization of signals that dictate nuclear/ nucleolar and cytoplasmic shuttling of the capsid protein of Tomato leaf curl Java virus associated with DNA beta satellite. Virus Res 2009, 144(12):145-153.

40. Haupt S, Stroganova T, Ryabov E, Kim SH, Fraser G, Duncan G, Mayo MA, Barker H, Taliansky M: Nucleolar localization of potato leafroll virus capsid proteins. J Gen Virol 2005, 86(Pt 10):2891-2896.

41. Liu JL, Lee LF, Ye Y, Qian Z, Kung HJ: Nucleolar and nuclear localization properties of a herpesvirus bZIP oncoprotein, MEQ. J Virol 1997, 71(4):3188-3196

42. Reed ML, Dove BK, Jackson RM, Collins R, Brooks G, Hiscox JA: Delineation and modelling of a nucleolar retention signal in the coronavirus nucleocapsid protein. Traffic 2006, 7(7):833-848

43. Guo YX, Dallmann K, Kwang J: Identification of nucleolus localization signal of betanodavirus GGNNV protein alpha. Virology 2003, 306(2):225-235.

doi:10.1186/1471-2105-12-317

Cite this article as: Scott et al: NoD: a Nucleolar localization sequence detector for eukaryotic and viral proteins. BMC Bioinformatics 2011 $12: 317$

\section{Submit your next manuscript to BioMed Central and take full advantage of:}

- Convenient online submission

- Thorough peer review

- No space constraints or color figure charges

- Immediate publication on acceptance

- Inclusion in PubMed, CAS, Scopus and Google Scholar

- Research which is freely available for redistribution

Submit your manuscript at www biomedcentral com/submit
C Biomed Central 